Check for updates

Cite this: RSC Adv., 2021, 11, 24570

Received 29th June 2021

Accepted 7th July 2021

DOI: $10.1039 / \mathrm{d} 1 \mathrm{ra05032j}$

rsc.li/rsc-advances

\section{Synthesis of functionalized benzo[1,3]dioxin-4- ones from salicylic acid and acetylenic esters and their direct amidation $\uparrow$}

\author{
Rasmi P. Bhaskaran, (D) Kalinga H. Nayak (D) and Beneesh P. Babu (D) *
}

Direct synthesis of $4 \mathrm{H}$-benzo[d] [1,3]dioxin-4-one derivatives from salicylic acids and acetylenic esters (both mono- and disubstituted) has been described. The reaction is mediated by $\mathrm{Cul}$ and $\mathrm{NaHCO}_{3}$ in acetonitrile. Room temperature amidation of the synthesized 1,3-benzodioxinones with primary amines readily afforded the corresponding salicylamides in moderate to good yields.
Heterocycles and their derivatives play a pivotal role in natural products and synthetic organic chemistry. Isolation, bio and chemical synthesis, and investigation of pharmacological and biological properties of diverse heterocycles have attracted both organic and medicinal chemists. ${ }^{1}$ It is a highly vibrant and everexpanding field of research. Besides, heterocycle scaffolds contribute significantly towards the development of novel organic materials for luminescent applications due to their unique photophysical properties, which can be tuned to suit diverse applications. ${ }^{2}$ Benzodioxans are oxygen-based isomeric heterocycles with various applications in medicinal, agricultural, and synthetic chemistry. Among the isomeric benzodioxans, 1,3-benzodioxane and its derivatives are used in medicinal and agrochemicals chemistry research. ${ }^{3}$ In addition, they are potential synthetic intermediates in multistep organic synthesis. ${ }^{4}$ Among the various 1,3-benzodioxane derivatives, $4 H$-benzo[ $d][1,3]$ dioxin-4-one has been identified as an active core in many biologically active molecules such as nucleoside base transport inhibitor, topoisomerase I inhibitor, antiplasmodial and cytotoxic drugs, etc., and its thio derivatives find applications as an insecticide, crop protection agents, and fungicides. ${ }^{5}$ Few examples have been shown in Fig. 1.

Salicylic acid and its derivatives are widely used to access the $4 H$-benzo[ $[d][1,3]$ dioxin-4-one scaffolds, and several approaches have been reported in the literature. ${ }^{6}$ In a similar line, reports in which thiosalicylic acid yielding the corresponding benzo-1,3oxathiine derivatives are also reported. ${ }^{7}$ For example, conversion of salicylic acid to benzo[d][1,3]dioxin-4-ones using

Department of Chemistry, National Institute of Technology Karnataka - NITK, Surathkal 575025, Mangalore, India. E-mail: pbbeneesh@nitk.edu.in; Tel: +91-824-2473219

$\dagger$ Electronic supplementary information (ESI) available: General experimental information and procedure, full characterization data and spectra $\left({ }^{1} \mathrm{H}\right.$ and ${ }^{13} \mathrm{C}$ NMR) of all the products are available. CCDC 2084126. For ESI and crystallographic data in CIF or other electronic format see DOI: 10.1039/d1ra05032j dichloromethane as the methylene donor was reported by Xiuling Cui under catalyst-free condition using potassium phosphate. ${ }^{8}$ Later, Liu et al. developed a $\mathrm{Cu}(\mathrm{OAc})_{2}$ catalyzed approach based on ortho-halobenzoic acid, $\mathrm{KOH}$, and $\mathrm{NaHCO}_{3} .{ }^{9}$ Morpholine catalyzed conversion of salicylic acid to the benzodioxinone scaffold was reported by Qiu and co-workers treating with ynones. ${ }^{10}$ In 2017 , Kawatsura et al. reported the synthesis of 1,3-oxathiine derivatives via an iron-catalyzed intermolecular reaction between thiosalicylic acid and internal alkynes. ${ }^{11}$ Very recently, Muthusamy et al. reported a catalyst-free synthesis of 1,3-oxathiine derivatives by treating<smiles>COC1=CC(Cl)=C(C(C)=O)C2(OC(=O)c3c(O)cc(C)cc3O2)C1=O</smiles>
Maldoxin<smiles>CC1(C)OC(=O)c2ccc(N3C(=O)N(Cc4ccncc4)C(C)(C)C3=O)cc2O1</smiles>

Insulin receptor inhibitor<smiles>COc1cc2c(c(C)c1C)C(=O)O[C@@](C)([C@@H](C)C(=O)O)O2</smiles>

Synnemadoxin A<smiles>C=C(C)C1OC(=O)c2cc(C(C)=O)cc(OC)c2O1</smiles>

Antiplasmodial activity<smiles>[R]c1cccc2c1C(=O)OC(C)(C)S2</smiles>

Crop protection agents<smiles>COc1cc2c(c(C)c1CO)C(=O)O[C@@H](C(C)C(=O)O)O2</smiles>

Synnemadoxin B
Fig. 1 Bioactive molecules with 1,3-benzodioxinone or benzoxathiinone core. 
thiosalicylic acid and substituted propargylic alcohols. ${ }^{12}$ Due to our continued interest in the development of novel and modified synthetic routes to heterocycles, ${ }^{13}$ we herein report a modified route to synthesize benzo[ $d][1,3]$ dioxin-4-ones from salicylic acid and acetylenic esters. To the best of our knowledge, this is the first report on the synthesis of benzo[d][1,3] dioxin-4-ones from salicylic acid and acetylenic esters though the corresponding benzo-1,3-oxathiine route has already been documented. ${ }^{11}$ Interestingly, both mono- and disubstituted acetylenic esters were equally effective in the reaction. The benzo $[d][1,3]$ dioxin-4-ones derivatives synthesized further readily converted to amides when treated with primary amines at room temperature.

From the literature, we understand that the reaction between salicylic acid and acetylenic esters is not yet explored in detail though the analogous thiosalicylic acid-based methods have been well documented. We started our investigations using the salicylic acid 1a and dimethyl acetylenedicarboxylate (DMAD) $\mathbf{2 a}$ as the model substrates and the reaction optimization observations of the pilot experiment are summarized in Table 1. Stirring 1a $(0.6 \mathrm{mmol})$ and $2 \mathrm{a}(0.5 \mathrm{mmol})$ together in a Schlenk tube using acetonitrile $(2 \mathrm{ml})$ as the solvent resulted in no characteristic reaction at room temperature as well as at $80{ }^{\circ} \mathrm{C}$. We further introduced a base into the reaction medium. Both organic and inorganic bases were screened to identify the best condition. Organic bases such as pyridine and DABCO failed to afford the expected product under hot conditions. Interestingly, inorganic bases succeeded in yielding the expected benzo $[d]$
$[1,3]$ dioxin-4-one with moderate conversion. $\mathrm{NaHCO}_{3} \quad(1.2$ equiv.) was proved to be the best base for the reaction, yielding $55 \%$ of the product 3aa (Table 1, entry 5). We further studied the effect of different metal salts such as $\mathrm{CuI}, \mathrm{Pd}(\mathrm{OAc})_{2}, \mathrm{CuCl}, \mathrm{FeCl}_{3}$, $\mathrm{NiCl}_{2}$, and $\mathrm{MnCl}_{2}$ in the reaction. Among the various metal salts screened, CuI showed a remarkable influence on the outcome of the reaction as summarized in Table 1. Stoichiometric CuI (1 equiv.) as an additive in presence of $\mathrm{NaHCO}_{3}$ (1.2 equiv.) base enhanced the yield of the final benzo[d][1,3]dioxin-4-one derivative to $88 \%$ in $24 \mathrm{~h}$ (entry 8 ). We noticed that the presence of both $\mathrm{NaHCO}_{3}$ and $\mathrm{CuI}$ was crucial for the reaction as withdrawal of any one of the reagents affected the overall conversion (entries 5 and 9). Acetonitrile was finalized as the best solvent for the reaction after screening various solvents. THF and 1,2-DCE yielded the product in trace amount while methanol and DMSO failed to promote the reaction. In short, after a series of optimization experiments, we identified the best reaction condition for the synthesis of 3aa as treating $\mathbf{1 a}$ and $\mathbf{2 a}$ in acetonitrile in presence of $\mathrm{CuI}$ (1 equiv.) and $\mathrm{NaHCO}_{3}(1.2$ equiv.) at $80{ }^{\circ} \mathrm{C}$ for $24 \mathrm{~h}$.

With the optimized reaction conditions in hand, we subsequently explored the substrate scope of the reaction using various 2-hydroxy aromatic acids and acetylenic esters. Interestingly, both disubstituted acetylenic esters - such as DMAD 2a and diethyl acetylenedicarboxylate $\mathbf{2 b}$ - and monosubstituted acetylenic esters - such as methyl propiolate $2 \mathbf{c}$ and ethyl propiolate $\mathbf{2 d}$ - were equally effective in the optimized conditions affording the benzo[ $d][1,3]$ dioxin-4-one derivatives in moderate

Table 1 Optimization of the reaction conditions ${ }^{a}$

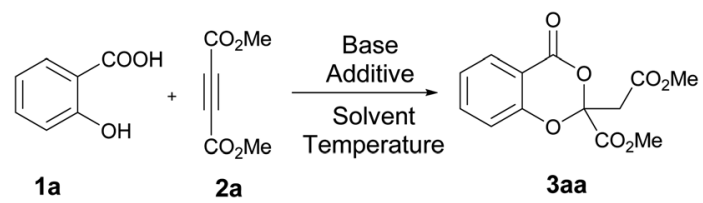

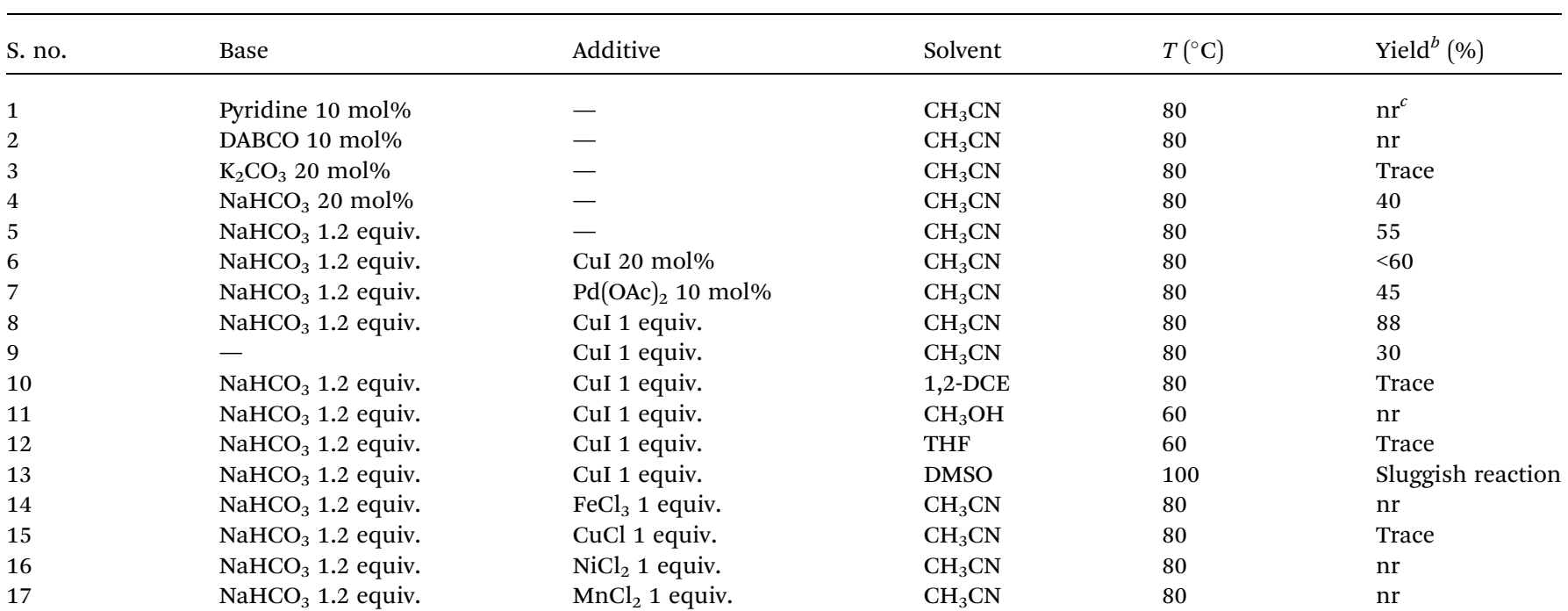

${ }^{a}$ All reactions were carried out in a Schlenk tube in $0.5 \mathrm{mmol}$ scale. Reaction conditions: 1a (1.2 equiv.), 2a (1 equiv.), base (1.2 equiv.), additive (1 equiv.), solvent $(2 \mathrm{ml}), 24 \mathrm{~h}, 80{ }^{\circ} \mathrm{C} .{ }^{b}$ Isolated yield after column chromatography is reported. ${ }^{c}$ nr: no reaction. 
Table 2 Synthesis of benzo[d][1,3]dioxin-4-ones ${ }^{a}$

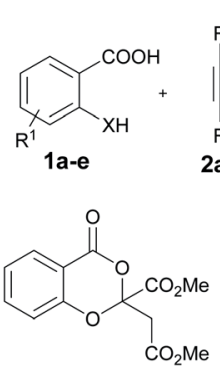

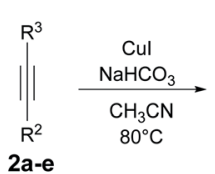

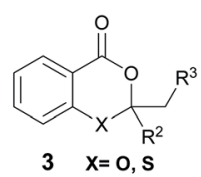<smiles>CCOCC1(OCC)OC(=O)c2ccccc2O1</smiles><smiles>CC(=O)CC1OC(=O)c2ccccc2O1</smiles>

3aa, $88 \%$ 3ab, $72 \%$ $3 a c, 63 \%$<smiles>CCOC(=O)c1ccccc1OC(CCN)(OC(=O)c1ccccc1)c1ccccc1</smiles><smiles>CC(=O)CC1(C(C)=O)OC(=O)c2ccccc2S1</smiles><smiles>CCOC(=O)CC1OC(=O)c2ccc(OC)cc2O1</smiles><smiles>CC(=O)CC1(C(C)=O)OC(=O)c2ccc(Br)cc2O1</smiles><smiles>CC(=O)CC1(C(C)=O)OC(=O)c2cc3ccccc3cc2O1</smiles>
$3 \mathrm{da}, 60 \%$<smiles>CC(=O)CC1OC(=O)c2cc3ccccc3cc2O1</smiles>

$3 \mathrm{dc}, 46 \%$
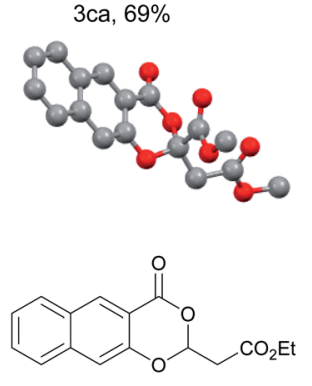

$3 \mathrm{dd}, 65 \%$
${ }^{a}$ All reactions were carried out in a Schlenk tube. Reaction conditions: 1a (1.2 equiv.), alkyne (1 equiv.), $\mathrm{NaHCO}_{3}$ (1.2 equiv.), $\mathrm{CuI}$ (1 equiv.), acetonitrile $(2 \mathrm{ml}), 24 \mathrm{~h}, 80{ }^{\circ} \mathrm{C}$. Isolated yield after column chromatography is reported.

to good yields (Table 2). Surprisingly, the hindered 3-phenylpropiolonitrile $2 \mathbf{e}$ in place of acetylenic esters also afforded the expected product in $55 \%$ yield. However, ethyl phenylpropiolate, phenylacetylene and acetylenic ketone such as 4phenylbut-3-yn-2-one failed to yield the product. Apart from salicylic acid, substituted salicylic acids - 4-methoxy derivative $\mathbf{1 b}$ and 4-bromo derivative 1c - were also used in the reaction. The former afforded $36 \%$ of the final product while the latter yielded 69\%. Electron deficient 2-hydroxy-3-nitrobenzoic acid and 3-hydroxypicolinic acid were not successful in the reaction as the former yielded a sluggish reaction mixture while the latter didn't react at all. Interestingly, the hindered 3-hydroxy-2naphthoic acid 1d reacted efficiently with both DMAD and ethyl propiolate with good conversion. However, with thiosalicylic acid 1e, conversion was moderate with DMAD and very low with methyl propiolate.

Surprisingly, an unexpected reactivity was observed when thiosalicylic acid is treated with 3-phenylpropiolonitrile $2 \mathbf{e}$
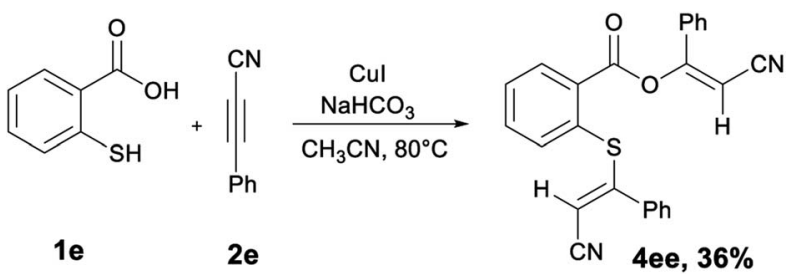

Scheme 1 Reaction between thiosalicylic acid and 3phenylpropiolonitrile.

under the optimized reaction conditions. Contrary to the expected 1,3-benzothiinone, the 1:2 adduct 2-cyano-1phenylvinyl(2-(2-cyano-1,2-diphenylvinyl)-thio)benzoate (4ee) was obtained as the final product (Scheme 1).

The $4 H$-benzo[ $d][1,3]$ dioxin-4-one derivatives are widely used in synthetic organic chemistry as a versatile synthetic intermediate. A spectrum of compounds such as amide, ester, alcohol, aldehyde etc. can be easily accessed from the 1,3-benzodioxinone derivatives. ${ }^{\mathbf{1 4}}$ We were particularly interested in their conversion to amides, because salicylamides are widely used in medicinal chemistry as various receptor inhibitors. ${ }^{15}$ Keeping this in mind, we treated the final 1,3-benzodioxinones with various amines expecting easy access to salicylamides. Following the literature procedure of amide synthesis, ${ }^{16}$ we treated 3aa and $n$-propylamine $\mathbf{5 a}$ in presence of DMAP (10 mol\%) and DBU (1 equiv.) in acetonitrile at room temperature for $8 \mathrm{~h}$. The reaction was successful and the expected salicylamide was formed in good yield (Table 3). The strategy was quite versatile and other primary amines such as isopropylamine $\mathbf{5 b}$, benzylamine $\mathbf{5 c}$ and cyclohexylamine $\mathbf{5 d}$ readily afforded the salicylamide in moderate to good yield. At the same time, secondary amines such as diethylamine and diphenylamine were not very effective. 1,3-Benzodioxinones derived from both salicylic acid and 3-hydroxy-2-naphthoic acid yielded the amide at room temperature. However, attempt to

Table 3 Synthesis of salicylamides from 1,3-benzodioxinones ${ }^{a}$

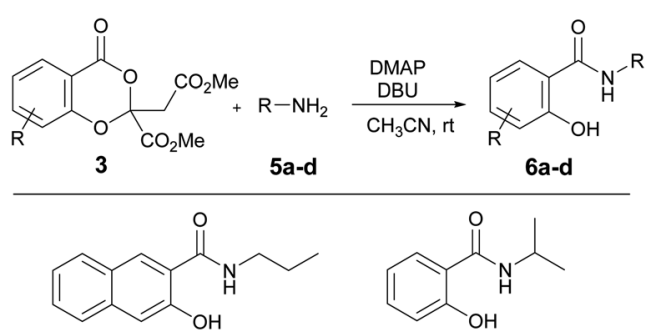

$6 a, 80 \%$

$6 b, 56 \%$

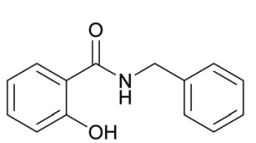

$6 c, 69 \%$<smiles>O=C(NC1CCCCC1)c1cc2ccccc2cc1O</smiles>

$6 d, 51 \%$
${ }^{a}$ Reaction conditions: 3 ( 1 equiv.), amine (1.1 equiv.), DMAP (10 mol\%), DBU ( 1 equiv.), acetonitrile $(4 \mathrm{ml}) 8 \mathrm{~h}$, rt. Isolated yield after column chromatography is reported. 


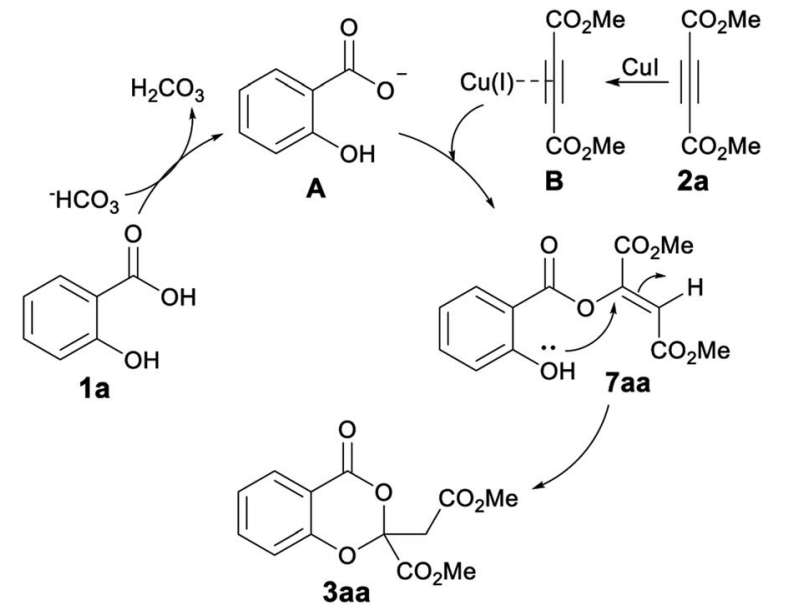

Scheme 2 Plausible reaction pathway.

perform the amide synthesis in a one-pot, two step process, without isolating the 1,3-benzodioxinone was less effective as the amide $\mathbf{6 a}$ was formed in $35 \%$ yield. It is noteworthy that the previous reports on the conversion of 1,3-benzodioxinones to amide involved treating the reagents in refluxing toluene while the present methodology made it feasible at room temperature itself. ${ }^{15}$ However, our initial results show that the method is best suited for aliphatic primary amines as the poor conversion was observed with anilines and secondary amines.

A plausible reaction mechanism is shown in Scheme 2 based on the control experiment conducted. The initial event is the acid deprotonation of $\mathbf{1 a}$ by the base. ${ }^{17}$ The carboxylate then adds to the $\mathrm{Cu}(\mathrm{I})$ coordinated alkyne to afford the linear adduct 7aa which was isolated, characterized and compared with the literature reports. ${ }^{18}$ The linear adduct subsequently undergoes intramolecular cyclization with ortho-hydroxyl group generating the final product.

\section{Conclusions}

In summary, an efficient and modified strategy for $4 H$-benzo $[d]$ $[1,3]$ dioxin-4-one derivatives has been developed. The method involves a $\mathrm{CuI}$ mediated addition between salicylic acid and acetylenic esters in a basic medium followed by intramolecular cyclization. Disubstituted acetylenic esters and monosubstituted propionic esters are equally effective in the reaction. The $4 H$-benzo[ $d][1,3]$ dioxin-4-one derivatives were further converted into salicylamides by treating with primary amines at room temperature. Investigation to expand the scope of this reaction further is underway in our lab.

\section{Conflicts of interest}

There are no conflicts to declare.

\section{Acknowledgements}

B. P. B. acknowledges the Department of Science and Technology (DST), Government of India for an INSPIRE Faculty
Award (IFA-13 CH-98). B. P. B., R. P. B., and K. H. N. thank NITK, Surathkal for providing laboratory facility and research fellowships for R. P. B. and K. H. N. The authors also thank NIISTCSIR Trivandrum, STIC-CUSAT Kochi, CIF-Manipal and NMR Centre, Mangalore University for spectra.

\section{Notes and references}

1 (a) Special Issue: Heterocyclic Chemistry, Eur. J. Org. Chem., 2019, 31-32, 4973-4975; (b) T. Kunied and H. Mutsanga, in The Chemistry of Heterocyclic Compounds, Academic Press, Palmer, 2002; (c) N. Panda, P. Mishra and I. Mattan, J. Org. Chem., 2016, 81, 1047-1056.

2 (a) X. Ke, L. Meng, X. Wan, Y. Sun, Z. Guo, S. Wu, H. Zhang, C. Li and Y. Chen, Mater. Chem. Front., 2020, 4, 3594-3601; (b) A. Pron, P. Gawrys, M. Zagorska, D. Djurado and R. Demadrille, Chem. Soc. Rev., 2010, 39, 2577-2632; (c) A. Mishra and P. Bäuerle, Angew. Chem., Int. Ed., 2012, 51, 2020-2067.

3 (a) R. G. Dushin and S. J. Danishefsky, J. Am. Chem. Soc., 1992, 114, 655-659; (b) S. W. Kang, C. M. Gothard, S. Maitra, A.-t. Wahab and J. S. Nowick, J. Am. Chem. Soc., 2007, 129, 1486-1487; (c) G. C. Clososki, C. J. Rohbogner and P. Knochel, Angew. Chem., Int. Ed., 2007, 46, 7681-7684.

4 (a) T. Yoshino, I. Sato and M. Hirama, Org. Lett., 2012, 14, 4290-4292; (b) D. C. Elliott, T. K. Ma, A. Selmani, R. Cookson, P. J. Parsons and A. G. M. Barrett, Org. Lett., 2016, 18, 1800-1803; (c) P. A. Evans, M. H. Huang, M. J. Lawler and S. Maroto, Nat. Chem., 2012, 4, 680-684.

5 (a) R. Cookson, T. N. Barrett and A. G. M. Barrett, Acc. Chem. Res., 2015, 48, 628-642; (b) G. Attardo, B. Zacharie, R. Rej, J. F. Lavallee, L. Vaillancourt, R. Denis and S. Levesque, US Pat., US2003013660(A1), 2003; (c) M. A. Tasdelen and Y. Yagci, ACS Macro Lett., 2017, 6, 1392-1397; (d) T. S. Cooper, B. Atrash, P. Sheldrake, P. Workman and E. McDonald, Tetrahedron Lett., 2006, 47, 2241-2243.

6 (a) J. S. S. Rountree and P. V. Murphy, Org. Lett., 2009, 11, 871-874; (b) J. K. Augustine, Y. A. Naik, A. B. Mandal, N. Chowdappa and V. B. Praveen, J. Org. Chem., 2007, 72, 9854-9856; (c) M. J. Fan, G. Q. Li and Y. M. Liang, Tetrahedron, 2006, 62, 6782-6791; (d) H. H. Wang, T. Shi, W. W. Gao, H. H. Zhang, Y. Q. Wang, J. F. Li, Y. S. Hou, J. H. Chen, X. Peng and Z. Wang, Org. Biomol. Chem., 2017, 15, 8013-8017; (e) L. Qui, X. He and M. Wang, Faming Zhuanli Shenqing, Chines Patent, CN 108383827, 2018.

7 Y. Nishina and J. Miyata, Synthesis, 2012, 44, 2607-2613.

8 F. Lin, Q. Song, Y. Gao and X. Cui, RSC Adv., 2014, 4, 1985619860.

9 Y. Liu, M. Huang and L. Wei, New J. Chem., 2017, 41, 47764778.

10 (a) X. He, Y. Li, M. Wang, H. X. Chen, B. Chen, H. Liang, Y. Zhang, J. Pang and L. Qiu, Org. Biomol. Chem., 2018, 16, 5533-5538; (b) V. K. Tripathi, P. S. Venkataramani and G. Mehta, J. Chem. Soc., Perkin Trans. 1, 1979, 36-41.

11 T. Sonehara, S. Murakami, S. Yamazaki and M. Kawatsura, Org. Lett., 2017, 19, 4299-4302. 
12 S. Muthusamy, M. Malarvizhi and E. Suresh, Org. Biomol. Chem., 2021, 19, 1508-1513.

13 (a) J. C. Janardhanan, R. K. Mishra, G. Das, S. Sini, P. Jayamurthy, C. H. Suresh, V. K. Praveen, N. Manoj and B. P. Babu, Asian J. Org. Chem., 2018, 7, 2094-2104; (b) J. C. Janardhanan, K. James, A. Puthuvakkal, R. P. Bhaskaran, C. H. Suresh, V. K. Praveen, N. Manoj and B. P. Babu, New J. Chem., 2019, 43, 10166-10175; (c) U. Amrutha, B. P. Babu and S. Prathapan, J. Heterocycl. Chem., 2019, 56, 3236-3243; (d) R. P. Bhaskaran, J. C. Janardhanan and B. P. Babu, ChemistrySelect, 2020, 5, 4822-4825.

14 (a) O. Soltani and J. K. De Brabander, Angew. Chem., Int. Ed., 2005, 44, 1696-1699; (b) N. Bajwa and M. P. Jennings, J. Org. Chem., 2006, 71, 3646-3649; (c) J. Spengler, J. RuízRodríguez, F. Yraola, M. Royo, M. Winter, K. Burger and F. Albericio, J. Org. Chem., 2008, 73, 2311-2314.
15 (a) K. D. Combrink, H. B. Gulgeze, K. L. Yu, B. C. Pearce, A. K. Trehan, J. Wei, M. Deshpande, M. Krystal, A. Torri, G. Luo, C. Cianci, S. Danetz, L. Tiley and N. A. Meanwell, Bioorg. Med. Chem. Lett., 2000, 10, 1649-1652; (b) M. S. Deshpande, J. Wei, G. Luo, C. Cianci, S. Danetz, A. Torri, L. Tiley, M. Krystal, K. L. Yu, S. Huang, Q. Gao and N. A. Meanwell, Bioorg. Med. Chem. Lett., 2001, 11, 2393-2396; (c) D. Balan, C. J. Burns, N. G. Fisk, H. Hügel, D. C. S. Huang, D. Segal, C. White, J. Wagler and M. A. Rizzacasa, Org. Biomol. Chem., 2012, 10, 8147-8153.

16 X. Yang and V. B. Birman, Org. Lett., 2009, 11, 1499-1502.

17 (a) H. Liang, X. He, Y. Zhang, B. Chen, J. Ouyang, Y. Li, B. Pan, C. V. S. Reddy, W. T. K. Chan and L. Qiu, Chem. Commun., 2020, 56, 11429-11432; (b) X. Xu, R. Sun, S. Zhang, X. Zhang and W. Yi, Org. Lett., 2018, 20, 1893-1897. 18 See ESI $\dagger$ for more details about control experiment and spectral data of the intermediate. 